CORIGINAL ARTICLE

Volume 14 Issue 22019

DOI: 10.21315/aos2019.14.2.383

ARTICLE INFO

Submitted: $13 / 05 / 2019$

Accepted: 02/12/2019

Online: 30/12/2019

\section{Experiences of Left-Handed Undergraduates in a Dental Faculty in Malaysia}

\author{
Wan Mohamad Nasira ${ }^{\mathrm{a}}$ Azlan Jaafar ${ }^{\mathrm{a}}$, Rahimah Abd Wahab ${ }^{\mathrm{a}}$, \\ Khairunnisa' Harun a , Aws Hashim Ali ${ }^{\mathrm{b}}$ \\ ${ }^{a}$ Department of Periodontology and Community Oral Health, \\ Faculty of Dentistry, Universiti Sains Islam Malaysia, \\ 55100 Kuala Lumpur, Malaysia \\ ${ }^{b}$ Department of Conservative Dentistry $\mathcal{E}$ Prosthodontics, \\ Faculty of Dentistry, Universiti Sains Islam Malaysia, \\ 55100 Kuala Lumpur, Malaysia
}

${ }^{\star}$ Corresponding author: drazlan_jaafar@usim.edu.my

To cite this article: Nasir WM, Jaafar A, Abd Wahab R, Harun K, Ali AH (2019). Experiences of left-handed undergraduates in a dental faculty in Malaysia. Arch Orofac Sci, 14(2): 147-156. https://doi. org/10.21315/aos2019.14.2.383

To link to this article: https://doi.org/10.21315/aos2019.14.2.383

\begin{abstract}
Work environment in dentistry benefits the right-handed dental practitioners. This situation requires the left-handers to work in an adjusted position causing them discomfort and inconvenience. The aim of this study was to explore the experiences of the identified left-handed undergraduate dental students in Faculty of Dentistry, Universiti Sains Islam Malaysia (USIM) in performing dental procedures. The first phase of the study was to determine handedness of the students using the Edinburgh Handedness Inventory Questionnaire that was distributed to all the dental students. This was followed by a qualitative study using the phenomenology approach. Semi-structured interviews were conducted on left-handed students to determine their perceptions on left-handedness in performing dental procedures. The number of students interviewed was based on attainment of the saturation point. The interview was recorded and transcribed verbatim. The transcripts were analysed through coding, categorising and grouping responses into themes. Prevalence of left-handedness in this faculty was $7 \%$. The participants were not aware of the right-handed situation when they enrolled in the faculty. This situation gave rise to psychological impact such as anxiety and stress. Although some participants were able to use their right hand for certain procedures, the dominant hand continued to be their preference. The difficulties encountered when using the non-dominant hand were grip-strength, angulation and positioning of the instruments. Dental procedures in periodontology (such as scaling, root debridement) and oral surgery (tooth extraction, incision and suturing) were found to be very challenging. They experienced muscle fatigue, reduced precision and prolonged time to complete the dental procedures. They felt that they should be given more time to adapt using the right hand under the tutelage of left-handed faculty members. Left-handed dental students faced difficulties in adapting to the right-handed situation and affect their effectiveness and efficiency. Specific activities need to be designed for left-handers to adapt to the situation under the guidance of left-handed faculty members.
\end{abstract}

Keywords: Left-handedness; dental students; psychological; dental procedures; grip-strength. 


\section{INTRODUCTION}

Left-handedness is the condition whereby the left-hand is more dominant than the right hand. It is the tendency or preferred hand for use in everyday activities to produce better, faster and more precise output than the right hand (Kaya and Orbak, 2004). The prevalence of left-handedness among world population ranged between $8 \%-15 \%$ (Hardyck and Petrinovich, 1977; Lansky et al., 1988; McManus et al., 2010). It was found that in Malaysia, 7\% of the population were left-handers (Kamarul et al., 2006). In dentistry, the proportion of left-handed dental practitioners ranged from $7 \%$ to $10 \%$ (Al-Johany, 2013; Silva et al., 2016; Sultane et al., 2017). To our knowledge there is no study to indicate the prevalence of lefthandedness among dental practitioners in Malaysia.

Work environment in dentistry is not conducive to the left-handed dental practitioner as the design of equipment and instruments are suited for the righthanded practitioners. Although some of this equipment are available for left-handers, the numbers produced is limited, costly and mostly installed in specialist dental clinics (Silva et al., 2012; Al-Johany, 2013). Considering that psychomotor skill in dentistry is of paramount importance, lefthanded dental practitioners must develop manual dexterity through manipulation of dental instruments to perform the required procedures (Kaya and Orbak, 2004). They must use their non-dominant hand to adapt to the right-handed environment. This situation compels the left-handers to work in an adjusted position that compromises on quality of care and may cause discomfort, inconvenience and other related problems (Silva et al., 2016; Samuel and Anandan, 2017). The left-handers face the dilemma of using their left-hand or change to the right hand to perform the dental procedures. Both situations affect the effectiveness and efficiency of the tasks they perform.
There is a dearth of studies on left handedness in dentistry. Most of the studies used the quantitative approach (Al-Johany, 2013; Kapoor et al., 2016; Sultane, et al., 2017). This approach does not describe the views on the problems faced by lefthanded dental undergraduates and how they adapt to the situation that qualitative studies offer. Therefore, this study was to explore the experiences of left-handedness among undergraduate dental students in an institution in Malaysia. It is expected that the findings of the study can guide the faculty to develop appropriate activities for left-handed students to cope with the situation.

\section{MATERIALS AND METHODS}

This was a cross-sectional mix-method study conducted among students of the Faculty of Dentistry, Universiti Sains Islam Malaysia (USIM). It was carried in two phases. The first phase comprised of quantitative study design to identify the left-handed students in the faculty. The second phase was the qualitative study that involved only the lefthanded student that were identified in the first phase.

The first phase of the study involved the use of Edinburgh Handedness Inventory Questionnaire (Oldfield, 1971). The questionnaire consisted of 10 items on hand preference in common daily tasks. All students from year one to year five were invited to participate in the study. Informed consent was obtained from all participants before they were instructed to fill up the questionnaire. They were asked to choose the hand preference for each item of the questionnaire by filling up the boxes of left or right hand with ' $\mathrm{x}$ ' for preference and ' $\mathrm{xx}$ ' for strong preference. Each questionnaire was scored by subtracting the total number of left-handed preferences from the righthanded preferences. This was then divided by the total number of items and multiplied by 100 as in the formula $[(R-L / R+L)$ 100]. A score of -100 to -40 indicated that the respondent was left-handed, -40 to 
+40 , ambidextrous and +40 to +100 , righthanded. The percentage, as a measure of descriptive statistics, was used to determine the prevalence of left-handedness in this institution based on the questionnaire.

In the second phase of the study, only left-handed students identified from this questionnaire were invited to participate. Informed consent was obtained from the participants before the semi-structured interview. A qualitative study based on the phenomenological approach was used to understand the problems faced by lefthanders and how they coped with them. The first participant for interview was based on most senior participant. The selection of subsequent participants for the interview adopted the snowballing technique. The first participant recommends the next participants. A consensus (agreement) of the other participants is taken into consideration. The process was repeated in selecting subsequent participants so that a smooth sequence of interviews was observed.

A semi-structured interview of the individual participants was conducted by RAW and $\mathrm{KH}$ for a period of 30 to 45 minutes. Both were trained to conduct qualitative interviews. These interviews were conducted using open-ended questions to encourage participants to recall their experiences. The questions were related to three fundamental aspects that included problems faced as a left-handed dental student, difficult dental procedures, and suggestions of experiences in coping with left-handedness during the duration of their study either in the laboratory or simulation laboratory or clinic. Additional questions were asked when necessary to gain better understanding of the responses. The interview provides avenues for discussion instead of direct questionanswer format.

A total number of 11 participants were involved for the interview based on the point of saturation whereby nothing new was revealed by the participants during the interview. The remaining two other participants were not included in the interview. The number of samples included for interview in this study was found to be adequate. The samples for phenomenological type of qualitative study was recommended to range from 5 to 25 participants (Morse, 1994; Creswell, 1998). The interview was conducted in English as the medium of instruction in this Faculty of Dentistry was English. It was recorded using audio recorder with permission from the participants and transcribed verbatim.

The data analysis was done after the completion of the interview to understand the overall perspective of the phenomena. The procedure on data analysis was based on the qualitative thematic analysis approach by Braun and Clark (2006). Following the interview, the data analysis was conducted after reading and rereading the transcribed data to understand and familiarise with the overall perspective of the phenomena. The analysis involved examining the text data and identify words or phrases for meaning. The related words or phrases for each code are collated into categories. Finally, the themes were formulated based on the relationships of the categories and a thematic map is generated.

The data and the results of the study were verified through triangulation. A panel consisting of a researcher familiar with qualitative research (WMN), a dental public health specialist $(\mathrm{AJ})$ and a clinical specialist (AHA) took part in the assessment of the data. It involved listening to the audio recording and reading the verbatim script as well as the notes of the interviewers for the panel to arrive at a consensus. The study was conducted from August to November 2018 after approval from the Ethical Committee vide its letter USIM/FPg-MEC/2016/No. (37) dated 10 August 2018.

\section{RESULTS}

The Edinburgh Handedness Inventory Questionnaire that was used in the first phase of the study were distributed to all 174 undergraduate dental students on 
August 2018. All the questionnaires were returned after it was collected by the two members of the research team, two weeks later at the end of August 2018. Analysis of the questionnaires showed that there were 13 left-handed students, equivalent to $7 \%$ of the undergraduate dental students (Table 1). When the number of left-handed between sex was analysed, female left-handers outnumbered male counterpart (Table 2).

Apart from the demographic characteristics presented in Table 1 on the year of study and Table 2 on sex, participants have a similar Islamic education background, belonged to Malay ethnic group and age range of 19 to 23 years old.

\section{Thematic Analysis}

The interview of the participants in the second phase of the study identified five major themes after the analysis of data. These themes included overall perception on left-handedness, categories of lefthandedness, difficulties encountered when performing procedures using left-hand, perceived effect when using the left-hand for dental procedures and suggestions to improve the situation are shown in Figure 1.

\section{Theme 1: Awareness of right-handedness in dentistry}

The participants claimed that before they enrolled at the Faculty of Dentistry, they were not aware that the work environment was not in their favour. They did not know the problems related to the use of left-hand in a situation designed for right-handers. They only realised the need to use the right hand in the early stage of their study when they started to be involved in the simulation sessions. They noticed that the position of handpiece of the dental simulator would make it more suitable for them to use their right-hand in performing the procedures.

\section{Theme 2: Level of confidence}

The participants were encouraged to use their right-hand when performing the clinical procedures but there was no compulsion to it. Three groups of left-handed participants could be identified in this dental faculty. The first group of left-handers were those who attempted to adapt to the situation by using their right-hand and not using their dominant hand entirely. They appeared to be affected psychologically; reported to experience apprehensiveness in adapting to

Table 1: Prevalence of handedness among USIM dental students

\begin{tabular}{lcccc} 
Year of study & \multicolumn{3}{c}{ Hand preference } & \multirow{2}{*}{ Total } \\
\cline { 2 - 4 } & Left & Ambidextrous & Right & \\
Year 1 & 3 & 2 & 30 & 35 \\
Year 2 & 1 & 2 & 32 & 35 \\
Year 3 & 2 & 3 & 30 & 35 \\
Year 4 & 3 & 2 & 29 & 34 \\
Year 5 & 4 & 2 & 29 & 35 \\
\hline Grand Total & $13(7 \%)$ & $11(6 \%)$ & $150(87 \%)$ & $174(100 \%)$ \\
\hline
\end{tabular}

Table 2: The number of handedness according to sex

\begin{tabular}{lccc} 
& \multicolumn{3}{c}{ Hand preference } \\
\cline { 2 - 4 } Sex & Left & Ambidextrous & Right \\
Male & $2(1.1 \%)$ & $3(1.7 \%)$ & $33(19.0 \%)$ \\
Female & $11(6.3 \%)$ & $8(4.7 \%)$ & $117(67.2 \%)$ \\
\hline
\end{tabular}




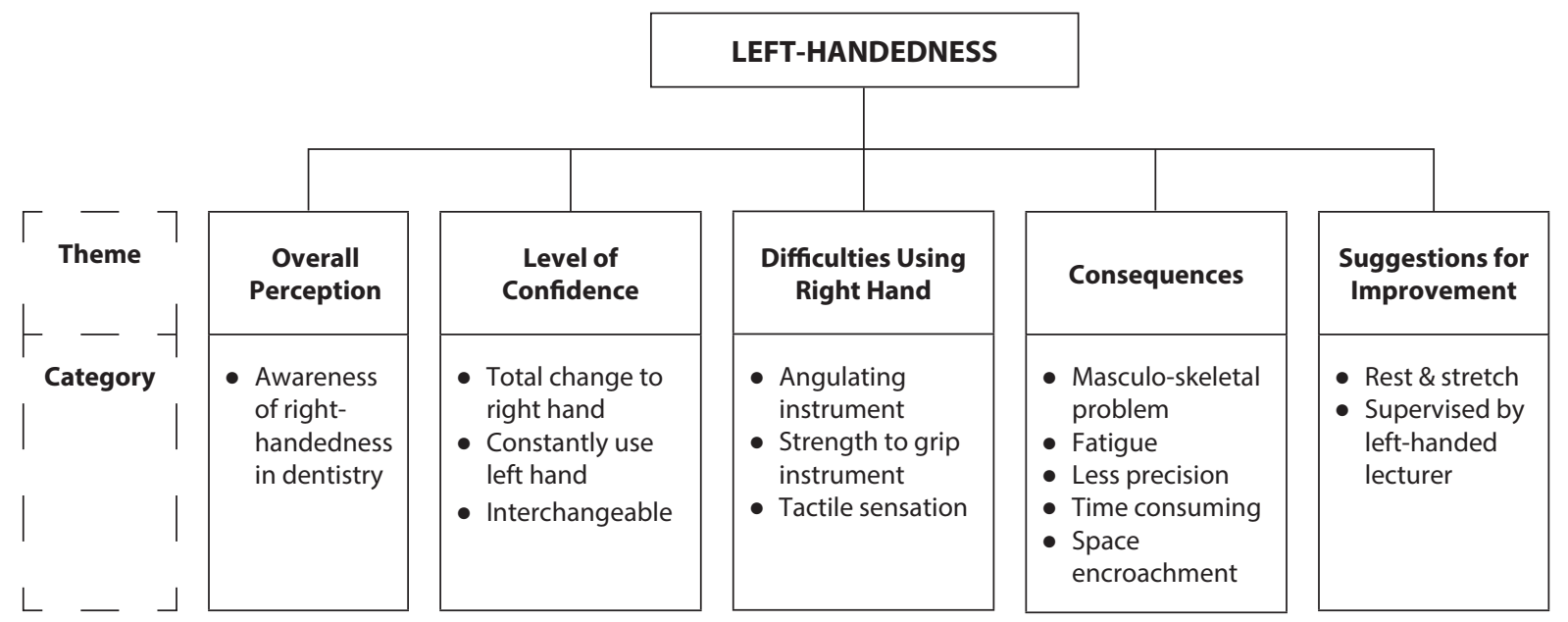

Figure 1 Overall perception on left-handedness.

the situation; and felt anxious and nervous when they performed the dental procedures with their right-hand. They also believed that their level of confidence was affected when they use their right hand to perform the procedures and tended to feel inferior to their right-handed peers because of reduced efficiency. Nevertheless, there were conflicting views regarding the performance of this first group of left-handers in terms of efficiency and effectiveness. They required more time to complete their work compared to the right-handers. They felt that their work was slower, and the result was unsatisfactory.

The second group of left-handers were those who were unable to adapt using their right hand. They continued to use their left hand in clinical practice; felt comfortable using it; claimed that they have more control over their hand; believed that they performed the procedure efficiently and effectively and were satisfied with their performance.

The third group of left-handed participants preferred to use their right hand in most dental procedures including using the handpiece for cavity preparation and scaling. However, they occasionally used their left hand for these procedures. They have almost adjusted in using their right hand and reported that they felt awkward at certain times when they use their left hand to perform the dental procedures.
However, there were some procedures that they felt more comfortable with their dominant hand and these procedures involved using instruments that were not part of the dental chair. Examples of the procedures included taking impression, using hand instruments and preparing the needle holder for suturing.

\section{Theme 3: Difficulties encountered when using right hand}

The procedures that they found difficult to perform were root debridement, use of needle holder for suturing and those procedures that involved handpiece such as scaling, cavity preparation and crown preparation. The problem associated with performing these procedures was in angulating the instruments.

The work area in the mouth that posed problems in performing the clinical procedures varied among the participants. They pointed out that this was also related to angulating the instruments.

The strength of the grip of the instruments was another difficulty encountered when performing the dental procedures. The participants lamented that their grip on the instruments was not strong enough when they use their right hand. They could feel the difference when comparing the two hands. 
They had difficulty in using their right hand for procedures that required a steady grip such as scaling, extraction, incision and using handpieces.

The participants claimed that their left hand had better tactile sensation than the right hand. They believed that tactile strength affects the outcome of their work. So, they preferred to use their dominant hand for procedures that required fine and controlled manipulations, such as filing of the root canal in endodontic treatment.

\section{Theme 4: Consequences}

Participants experienced some form of musculo-skeletal problems when using their right hand. They faced the problems of spasm, fatigue and pain on their right hand and back of body.

The participants felt the pain only after completion of the treatment because they were too engrossed with the procedure during the treatment. While some others felt fatigue on their right-hand during treatment.

The participants also raised their concern on precision of their work when performing with their non-dominant hand and that they needed to be more cautious to avoid any undesirable outcome. In such situation, they tended to use their left hand.

The participants described the early experiences in working with their right hand on the simulation laboratory. The outcome of the work did not conform to the standards of cavity preparation.

They said that they took longer time to complete a treatment procedure when compared to their friends. Besides, they felt better and comfortable with their dominant hand. It took some time to adapt using the right hand.

The participants who used their left hand in dental practice claimed that they encroached the work space of their assistants. This caused the assistants to have limited work space and view of the work area of the patient's mouth. This situation also caused the assistant to bend the body forward to have better view of the work area. The participants sometimes receive some complaints from their assistants regarding this problem.

The participant who used their left hand also claimed that the situation also caused the patient to feel uncomfortable. This was because the cable of the handpiece would be on the body of the patient during the treatment.

The participants sometimes overcome this problem by holding the handpiece extension with their right hand together with the other dental instrument such as mouth mirror.

\section{Theme 5: Suggestions for Improvement}

Some believed that they could overcome the problem of spasm and fatigue by taking a short rest and used their left hand for a short period of time. Similarly, treatment position could reduce the problem. They also said that they addressed their problems in dental practice to the left-handed supervisor and sought advice on how to adapt with the right-hand environment of dentistry. The advice was very helpful and increased their performance.

\section{DISCUSSION}

This cross-sectional mix-method study adopted the quantitative approach to objectively identify left-handers and then proceeded with the qualitative approach to elicit deeper insights on left-handedness among dental students at USIM with regard to their behaviours, perceptions and feelings.

Handedness questionnaires are used to determine the hand preference in performing the daily tasks by the subjects, that is whether they are right-handed, left-handed or ambidextrous. Flindall and Gonzalez (2019) identified two commonly used handedness questionnaires, namely the 
Edinburg Handedness Inventory (EHI) and Waterloo Handedness Questionnaire (WHQ) The advantages of EHI are its simplicity and brevity as well as it correlates with self-reports of the participants (Ransil and Schachter, 1994).

This study revealed that $7 \%$ of dental students in this institution were left-handed and similar to the prevalence of left-handers among dental students in Brazil (Silva et al., 2016). However, Al-Johany (2013) found that $6.6 \%$ of dental students in Saudi Arabian were left-handers. This was a slightly lower level of prevalence of lefthanders than in Malaysia and Brazil. All other countries reported higher prevalence of left-handed dental students, namely $8 \%$ in United Kingdom (Henderson et al., 1996) and $9.5 \%$ in India (Sultane et al., 2017). The prevalence of left-handed students in the dental faculty in Nigeria was $20.2 \%$, almost triple that of Malaysia and Brazil. It is pertinent to mention that both this and the Nigerian studies used the Edinburgh Handedness Inventory questionnaire (Alibeik and Angaji, 2010). The global prevalence of left-handedness has not yet been established (Odabas et al., 2012). However, it was estimated that $10 \%$ of the world's population are left handers (Lui et al., 2012). In Malaysia, left-handers formed $7 \%$ of the general population which is comparable with the prevalence of left-handers in this institution.

It was found that all left-handed dental students, irrespective of whether they change to working with the right hand or persist using their left hand or use both of their left or right hand according to their convenience felt that their left-handedness was a disadvantage in dentistry. It affected the efficiency, effectiveness and level of confidence when performing dental procedures. However, their efficiency, effectiveness and level of confidence tend to improve as they progressed in their course. This situation was consistent with the findings by Al-Lawati et al. (2019) that the left-handed dental students perceived their efficiency and level of confidence to be affected when performing the dental procedures in their early clinical years. They considered the left-handed participants as highly adaptable. Kaya and Orbak (2004) conducted a study on the performance of left-handed dental students on a common procedure. They found that the performance of left-handed dental students using the right-sided dental chair were not as good as those using the left-sided chair.

This study indicated that participants faced difficulties in handling dental instruments and equipment designed for right handers to perform the required procedures in the simulation laboratory or dental clinic. It affected the efficiency and effectiveness of the procedures due to reduced manual dexterity. Silva et al. (2016) found that slightly more than three-quarter of left-handed dental students had difficulties in performing the dental procedures as compared to $10 \%$ of right-handers. Even left-handed dental practitioners felt uncomfortable or inconvenient when using right-handed dental chair (Orbak et al., 2002).

The participants identified several procedures that reduced their manual dexterity. These procedures include scaling and root debridement (periodontology), suturing and manipulating extraction forceps (oral surgery) and handling handpieces. The problems they faced with these procedures were related to either manipulating the instruments or reduced strength of the grip of the instruments. It was found that almost half of left-handed dental students faced the problem of performing procedures in Periodontology course (Kaya and Orbak, 2004; Silva et al., 2016), slightly more than one-third of participants have difficulty in holding the extraction forceps, while $15 \%$ had difficulty to hold the suturing scissors. (Sultane et al., 2017).

The participants encountered with musculoskeletal problem when performing dental procedures. However, Puriene et al. (2008) pointed out that work-related musculoskeletal disorder (WRMD) commonly occurs among dental practitioners 
as the result of excessive use of muscular groups in repetitive motions, permanent segments in specific position for long period of time, and insufficient time for recovery. It was found that about two-thirds of lefthanded dental students and more than half of right-handed dental students were affected by pain in lumbar and cervical area and that the condition worsened in slow-adapting lefthanders (Sultane et al., 2017).

The participants considered the left-handed supervisors to play a crucial role in guiding them to perform the dental procedures in the manner that would not only be convenient to them but also to the patients and assistant. It was found that slightly more than half of participants felt uncomfortable with their right-handed instructors because of the inability to guide them (Sultane et al., 2017).

One of the limitations of this study was that the interview was conducted in English which is not the mother tongue of the students but the medium of instruction is English. The students from year one and year two were not yet exposed to the clinical set up of the dental chair and had no knowledge regarding the situation in the clinic. This study also did not compare the problems faced by the left-handed students with the right-handed students. Besides that, this study found three categories of left-handed dental students after analysis of the data. Therefore, we are unable to explore the different experiences of these three groups of left-handed dental students.

This study reveals the problems faced by left-handers in adapting themselves in righthanders. It provides some guide in improving the efficiency and effectiveness of left-handed students in pursuing the course in dentistry.

\section{CONCLUSION}

The prevalence of left-handedness in this institution was less than $10 \%$. There were three groups of left-handers namely, the genuine left-handers who continued using their left-hand; the pseudo-left-handers who switched hands performing the dental procedures; and the transformed lefthanders who have adapted using their right-hand. Left-handed dental students face difficulties in adapting to right-handed dental instruments and performing certain dental procedures. These difficulties may lead to short term complications related to ineffectiveness and inefficiency in performance; and long-term complications due to musculoskeletal disorders. It may also lead to inconvenience of the assistant and the patient. This study provides the faculty the necessary information to design educational activities for left-handers to adapt to the situation particularly under the guidance of left-handed faculty members.

\section{ACKNOWLEDGEMENTS}

The authors are most grateful to the Faculty of Dentistry, USIM for the approval and support to conduct this study.

\section{CONFLICT OF INTEREST}

The authors declare that they have no conflict of interest.

\section{REFERENCES}

Alibeik H, Angaji SA (2010). Developmental aspects of left-handedness. Aust $\mathcal{F}$ Basic Appl Sci, 4(5): 877-81.

Al-Johany SS (2013). A survey of left-handed dental students and interns in Saudi Arabia. F Dent Educ, 77(1): 105-112.

Al-Lawati I, Al-Maskari H, Ma S (2019). "I am a lefty in a right-handed world": Qualitative analysis of clinical learning experience of left-handed undergraduate dental students. Eur $\mathcal{F}$ Dent Educ, 23(3): 316-322. https:// doi.org/10.1111/eje.12432 
Braun V, Clarke V (2006). Using thematic analysis in psychology. Qual Res Psychol, 3(2): 77-101. https://doi. org/10.1191/1478088706qp063oa

Creswell JW (1998). Qualitative Inquiry and Research Design: Choosing Among Five Traditions. Thousand Oaks, CA: Sage Publications Ltd.

Flindall JW, Gonzalez CLR (2019). Wait wait, don't tell me: Handedness questionnaires do not predict hand preference for grasping. Laterality, 24(2): 176-196. https://doi.org/10.1080/135765 0X.2018.1494184

Hardyck C, Petrinovich LF (1977). Lefthandedness. Psychol Bull, 84(3): 385-404.

Henderson NJ, Stephens CD, Gale D (1996). Left-handedness in dental undergraduates and orthodontic specialists. $\mathrm{Br}$ Dent $\mathcal{F}$, 181(8): 285-288. https://doi.org/10.1038/ sj.bdj. 4809237

Kamarul T, Ahmad TS, Loh WY (2006). Hand grip strength in the adult Malaysian population. $\mathcal{f}$ Orthop Surg, 14(2): 172-177. https://doi. org/10.1177/230949900601400213

Kapoor S, Puranik MP, Uma SR (2016). Practice perspectives of left-handed clinical dental students in India. $\mathcal{F}$ Clin Diagn Res, 10(10): ZC79-ZC83. https://doi.org/10.7860/ JCDR/2016/17550.8664

Kaya MD, Orbak R (2004). Performance of lefthanded dental students is improved when working from the left side of the patient. Int $\mathcal{F}$ Ind Ergon, 33: 387-393. https://doi. org/10.1016/j.ergon.2003.09.006

Lansky LM, Feinstein H, Peterson JM (1988). Demography of handedness in two samples of randomly selected adults $(N=2083)$. Neuropsychologia, 26(3): 465-477. https:// doi.org/10.1016/0028-3932(88)90099-1
Lui DF, Baker JF, Nfila G, Perera A, Stephens $M$ (2012). Hand dominance in orthopaedic surgeons. Acta Orthop Belg, 78(4): 531-537.

McManus IC, Moore J, Freegard M, Rawles $R$ (2010). Science in the making: Right hand, left hand. III: Estimating historical rates of left-handedness. Laterality, 15(1-2): 186-208. https://doi. org/10.1080/13576500802565313

Morse JM (1994). Designing funded qualitative research. In: Denzin NK, Lincoln YS (eds.), Handbook of Qualitative Research, 2nd edn. Thousand Oaks, CA: Sage Publications Ltd, pp. 220-235.

Odabas B, Dildes N, Genc C, Veli I, Ozer T (2012). Handedness of orthodontists and its impact on practice. Cumhuriyet Dent $\mathcal{F}$, 15(3): 229-234.

Oldfield RC (1971). The assessment and analysis of handedness: The Edinburgh inventory. Neuropsychologia, 9(1): 97-113. https://doi. org/10.1016/0028-3932(71)90067-4

Orbak R, Tezel A, Canakci V, Tan U (2002). Right and left-handed dentists using rightand left-sided dental chairs in treatment of calculus. Int $\mathcal{F}$ Neurosci, 112(1): 15-30. https://doi.org/10.1080/00207450212020

Puriene A, Aleksejuniene J, Petrauskiene J, Balciuniene I, Janulyte V (2008). Selfreported occupational health issues among Lithuanian dentists. Ind Health, 46(4): 369-374. https://doi.org/10.2486/ indhealth.46.369

Ransil BJ, Schachter SC (1994). Test-retest reliability of the Edinburgh Handedness Inventory and Global Handedness preference measurements, and their correlation. Percept Mot Skills, 79(3 Pt 1): 1355-1372. https://doi.org/10.2466/ pms.1994.79.3.1355 
Samuel SG, Anandan S (2017). Plight of lefthanded dentists in clinical dentistry. $\mathcal{F}$ Oral Res, 6(10): 263. https://doi.org/10.17126/ joralres.2017.081

Silva EMA, Cruz IDS, Costa ICC, de Lima KC, de Araújo Souza GC, Fuscella MAP et al. (2016). Left-handed students and clinical practice in dentistry: Adaptations, difficulties and realities experienced in the academic environment. Open $\mathcal{F}$ Prev Med, 6(11):71895. https://doi.org/10.4236/ ojpm.2016.611023
Silva MA, Souza-Rodrigues RD, Lashowisk K, Oda M, Vieira GF (2012). Left-handed dental students. Braz Dent Sci, 15(4): 36-40. https://doi.org/10.14295/bds.2012. v15i4.853

Sultane P, Sen N, Bhat N, Patil V, Patel S, Patel $\mathrm{H}$ et al. (2017). Perspectives, realities, and difficulties in clinical practice experience of left-handed dental students in Udaipur, India. Int $\mathcal{F}$ Prev Clin Dent Res, 4(3): 179183. 